\title{
The Highly Selective Capture of Phosphopeptides by Zirconium Phosphonate-Modified Magnetic Nanoparticles for Phosphoproteome Analysis
}

\author{
Liang Zhao, Ren'an Wu, Guanghui Han, Houjiang Zhou, Lianbing Ren, \\ Ruijun Tian, and Hanfa Zou \\ National Chromatographic R and A Center, Dalian Institute of Chemical Physics, Chinese Academy of \\ Sciences, Dalian, China
}

The@aighly@elective@apture@f@hosphopeptides@romథroteolytic@igests@s@@reat@hallenge for@he@dentification@f@hosphoproteins@y@nass@pectrometry.@n@his@vork, $(\oplus h e @ i r c o n i u m$ phosphonate-modified@nagnetic $₫ \mathrm{e}_{3} \mathrm{O}_{4} / \mathrm{SiO}_{2}$ core/shell@anoparticles $₫$ have $₫$ een $@ y n t h e s i z e d$ and@uccessfully@pplied@or@he@elective@apture@f@hosphopeptides@rom@omplex@ryptic digests@f@roteins@efore@he@alysis@fAMALDI-TOF@mass@pectrometry@with@he@esired convenience@of@sampleChandling.@TheCratio@of@magnetic@nanoparticle@to@protein@and@the incubation@imeđfor@apturing@hosphopeptidesđrom@omplex@roteolytic@igests@vere@nvestigated,@nd@he@ptimized@anoparticle-to-protein@atio@nd@incubation@ime@ere@between $₫ 5: 1 \oplus 0$

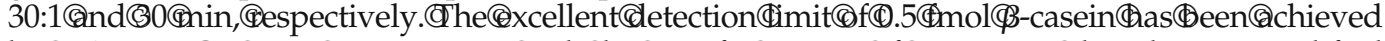
by@MALDI-TOF@nass@pectrometry@ith@he@pecific@apture@f@irconium@hosphonate-modified magnetic@ $\mathrm{Fe}_{3} \mathrm{O}_{4}$ nanoparticles.@The@great@specificity@of@zirconium@phosphonate-modified

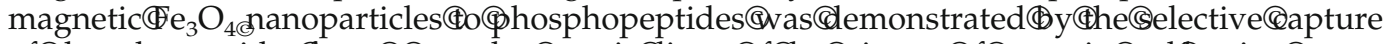
of@hosphopeptides@rom@@omplex@ryptic@igest@f@he@ixture@f@-casein@nd@ovine@erum

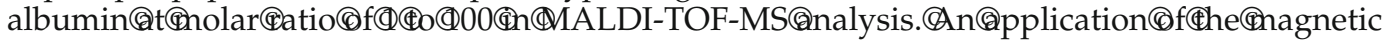
nanoparticles@o@elective@apture@hosphopeptides@rom@@ryptic@igest@f@nouseđiver@ysate was@urther@arried@ut@y@ombining@ith@iano-LC-MS/MS@nd@MS/MS/MS@nalyses,@nd a@total@of@194@unique@phosphopeptides@were@successfully@identified.@ (J@Am@Soc@Mass Spectrom(2008,@9,@176@1186)@(2008@American(\$ociety@or@Mass@Pectrometry

$\mathrm{P}$ ost-translational@nodifications@f@roteins@ontrol many@iological@rocesses.đThe@eversible@phosphorylation@f@roteins@s@ecognized@s@n@ssential@ost-translational@modification@egulating@ell@ignaling@and@1timately@unctions@f@iological@ystems [1].CThe@comprehensive@understanding@of@biological processes@equires@he@haracterization@f $\oplus$ rotein $థ$ hosphorylation@t@nolecular@evel.@Mass@pectrometry@s@ fundamental@ool@or@etecting@nd@mapping@heథhosphoryl@nodifications@fథroteins $\$ 2-5]$. $\$$ However, $9 u e \oplus$ the@ninimal@mount@f(phosphorylation@ound@n@roteins@and@the@serious@ion@suppression@phenomenon resulting@rom@he@roteolytic@omplexityథ6],@elective capture@f@hosphopeptides@rom@omplex@roteolytic products@has@een@emaining@uite@@hallenge@n@he field@f@roteomics.

Up@o@ow,@@ariety@f@pproaches@have@een@eveloped@or@elective@etermination@f@hosphopeptides@nd

Address@eprint@equests@o@r.@Hanfa@zou,@ational@hromatographic@R and@R@enter,Фalianđnstitute@f@hemical@hysics, @hinese@Academy@f Sciences, $\mathbb{}$ Dalian@1 16023.@China.CE-mail:Chanfazou@dicp.ac.cn@Or@tođDr.

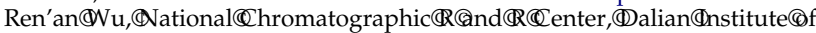
Chemical@Physics,@Chinese@Academy@of@sciences,@Dalian@16023.@hina. E-mail:@vurenan@dicp.ac.cn thus@mprove@he@etection@ensitivity@f@nass@pectrometry,@uch@s@hemical@erivatizationథ7-9],@mmunopre-

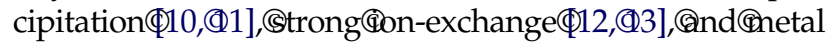

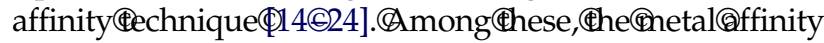
technique@sing@mmobilized@netal@ons@r@netal@xides asథhe@ffinity@noieties@o@hosphopeptides@vas@he@nost frequently@pplied@nethod,and@has@een@idely@pplied for@the@selective@capture@or@even@purification@of@phosphopeptides@ia@he@pecific@binding@between@he@netal moieties@and@the@phosphoryl@groups@of@peptides@and

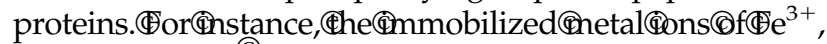
$\mathrm{Ga}^{3+}$, (and $₫ \mathrm{Zr}^{4+}$ On@hromatographic@dsorbents@howed the@specific@binding@characteristics@to@capture@phosphopeptides $\$ 20,\left(23,(24]\right.$, and $\oplus$ he@itanium@ioxide $\left.\Phi \mathrm{TiO}_{2}\right)$ and@irconium@ioxide $\left(\mathrm{ZrO}_{2}\right) @$ lemonstrated $₫$ he $@ i n d i n g$ specificity@o@hosphopeptides@f(he@omplex@roteolytic digests@ia@heథbidentate@interactions $\Phi 17-19]$.

Magnetic@nanoparticlesChave@been@extensively@applied@in@hemistry, (biochemistry, (biology, Cand@medicine,@uch@s@rug@arriers,@ioseparation,@ensors, @and enzymeđimmobilization@[25-28]@because@of@he@great convenience@f@perationsゆy@pplying@@nagneticథield and@long@vith@he@istinct@eatures@esulting@rom@he high@urface-to-volume@atio $\$ 29] . థ n థ h o s p h o p r o t e o m e$, 
the magnetic nanoparticles have been implemented for the selective capture and/or enrichment of phosphopeptides from the complex proteolytic digests by using the metal affinity technique for mass spectrometry. For example, Chen et al. $[17,18]$ used the $\mathrm{TiO}_{2}$ and $\mathrm{ZrO}_{2}$-coated iron oxide magnetic nanoparticles as the effective affinity probes for the selective concentration of phosphopeptides from the tryptic protein digests in MALDI-TOF MS with a low-femtomole limit of detection; Tan et al. [30] directly employed the $\mathrm{TiO}_{2}$-modified magnetic nanoparticles on MALDI targets, which was also demonstrated the specific capture and confident detection of phosphopeptides in MALDI-TOF-MS.

Recently, a new method for the specific trapping of phosphopeptides from the proteolytic digests was developed using the $\mathrm{Zr}^{4+}$-IMAC adsorbents, which showed higher specificity for phosphopeptides compared with $\mathrm{ZrO}_{2}$ and $\mathrm{TiO}_{2}$ beads $[15,19,23]$. Here, the zirconium-phosphate $\left(\mathrm{Zr}^{4+}-\mathrm{PO}_{3}\right)$-modified magnetic $\mathrm{Fe}_{3} \mathrm{O}_{4} / \mathrm{SiO}_{2}$ (core/shell) nanoparticles were synthesized for highly selective capture of phosphopeptides from protein digests. The synthesized magnetic nanoparticles were first evaluated with tryptic digests of ovalbumin and $\alpha$ - and $\beta$-caseins, and then were further applied for the analysis of phosphopeptides with the tryptic digest of a mouse liver lysate for the phosphoproteome analysis.

\section{Experimental}

\section{Materials and Reagents}

$\alpha$-Casein and $\beta$-casein (from bovine milk), trypsin, bovine serum albumin (BSA), 2,5-dihydroxybenzoic acid (2,5$\mathrm{DHB})$, zirconium oxychloride $\left(\mathrm{ZrOCl}_{2} \cdot 8 \mathrm{H}_{2} \mathrm{O}\right)$, tetraethoxysilane (TEOS), 2,4,6-collidine, and 3-aminopropyltriethoxysilane (APTES) were purchased from SigmaAldrich (St. Louis, MO). Urea, ammonium bicarbonate, dithiothreitol (DTT), and iodoacetamide (IAA) were purchased from BioRad (Hercules, CA). Iron (III) chloride hexahydrate $\left(\mathrm{FeCl}_{3} \cdot 6 \mathrm{H}_{2} \mathrm{O}\right)$, iron (II) chloride tetrahydrate $\left(\mathrm{FeCl}_{2} \cdot 4 \mathrm{H}_{2} \mathrm{O}\right)$, ammonium hydroxide, and phosphorus oxychloride $\left(\mathrm{POCl}_{3}\right)$ were obtained from Tianjin Chemical Plant (Tianjin, China). Acetonitrile, ethanol and trifluoroacetic acid (TFA) were purchased from Merck (Darmstadt, Germany). Water used in all experiments was doubly distilled and purified by a Milli-Q system (Millipore, Milford, MA).

\section{Synthesis of $\mathrm{Fe}_{3} \mathrm{O}_{4}$ Magnetic Nanoparticles}

The $\mathrm{Fe}_{3} \mathrm{O}_{4}$ magnetic nanoparticles were synthesized using a literature procedure [17] with certain small modifications. Briefly, $\mathrm{FeCl}_{2} \cdot 4 \mathrm{H}_{2} \mathrm{O}(2.0 \mathrm{~g})$ and $\mathrm{FeCl}_{3} \cdot 6 \mathrm{H}_{2} \mathrm{O}(5.4 \mathrm{~g})$ were first dissolved in a $2 \mathrm{M}$ hydrochloric acid solution $(25 \mathrm{~mL})$, which was then sufficiently degassed with a nitrogen stream. After that, a $25.0 \%$ (vol/vol) ammonium hydroxide solution (30 $\mathrm{mL}$ ) was added to the solution for a 30 min reaction at $60{ }^{\circ} \mathrm{C}$ with vigorous stirring under a nitrogen atmo- sphere. After cooling to ambient temperature, the resultant magnetic nanoparticles were attracted at the bottom by a magnet. Followed by the rinse with sufficient water for three times, the magnetic nanoparticles were finally resuspended in $50 \mathrm{~mL}$ water to give a suspension of ca. $40 \mathrm{mg} / \mathrm{mL}$ of magnetic nanoparticle in water.

\section{Preparation of $\mathrm{SiO}_{2}$-Shell on $\mathrm{Fe}_{3} \mathrm{O}_{4}$ Magnetic Nanoparticles}

The above-obtained $\mathrm{Fe}_{3} \mathrm{O}_{4}$ magnetic nanoparticles (40 $\mathrm{mg} / \mathrm{mL}, 5 \mathrm{~mL}$ ) were washed twice with ethanol, and resuspended in ethanol $(80 \mathrm{~mL})$ with $1 \mathrm{~h}$ sonication. Followed by a sequential addition of ammonia (25\%, $8.95 \mathrm{~mL})$, water $(7.5 \mathrm{~mL})$, and TEOS $(1.0 \mathrm{~mL})$, the resulting mixture was stirred vigorously for $2 \mathrm{~h}$ on a water bath at $40{ }^{\circ} \mathrm{C}$. The resultant magnetic $\mathrm{Fe}_{3} \mathrm{O}_{4} / \mathrm{SiO}_{2}$ core-shell nanoparticles were then rinsed with ethanol (30 $\mathrm{mL})$ three times and resuspended in ethanol (30 $\mathrm{mL}$ ), and subsequently followed by a $12 \mathrm{~h}$ reflux at $60{ }^{\circ} \mathrm{C}$ to strengthen the $\mathrm{Si}-\mathrm{O}-\mathrm{Fe}$ bonds. The above procedures were repeated once more to ensure the sufficient cover of $\mathrm{SiO}_{2}$ shell on $\mathrm{Fe}_{3} \mathrm{O}_{4}$ magnetic nanoparticles.

\section{Functionalization of Magnetic $\mathrm{Fe}_{3} \mathrm{O}_{4} / \mathrm{SiO}_{2}$ Core/Shell Nanoparticles}

The above produced $\mathrm{Fe}_{3} \mathrm{O}_{4} / \mathrm{SiO}_{2}$ core/shell magnetic nanoparticles were dried under vacuum at $60{ }^{\circ} \mathrm{C}$ for $12 \mathrm{~h}$ and dispersed in dry toluene $(45 \mathrm{~mL})$ with sonication. Followed by an addition of APTES $(1.5 \mathrm{~mL})$, the mixture was refluxed at $110{ }^{\circ} \mathrm{C}$ for $12 \mathrm{~h}$ under a nitrogen atmosphere. After cooled to ambient temperature, the resultant nanoparticles were washed with dry toluene, water and ethanol twice, respectively. With a further drying process in a vacuum oven at room temperature, the dried aminopropyl-modified magnetic nanoparticles were incubated in an anhydrous acetonitrile solution $(50 \mathrm{~mL})$ containing $40 \mathrm{mM} \mathrm{POCl}_{3}$ and $40 \mathrm{mM}$ 2,4,6-collidine at ambient temperature for $12 \mathrm{~h}$. After rinsing with $\mathrm{ACN}$ and water, respectively, the resultant phosphonate-modified nanoparticles were incubated in a $50 \mathrm{mM} \mathrm{ZrOCl}{ }_{2}$ solution with gentle stirring overnight for the loading of $\mathrm{Zr}^{4+}$ cations. Finally, the prepared zirconium-phosphonate-modified nanoparticles were rinsed with deionized water to remove the nonspecifically adsorbed $\mathrm{Zr}^{4+}$ cations, and dried under vacuum at $30{ }^{\circ} \mathrm{C}$ for $12 \mathrm{~h}$.

\section{Tryptic Digestion of Proteins}

$\alpha$-Casein and $\beta$-casein $(1 \mathrm{mg})$ were respectively dissolved in a $1 \mathrm{~mL}$ of ammonium bicarbonate buffer (50 $\mathrm{mM}, \mathrm{pH} 8.2$ ), and digested at $37^{\circ} \mathrm{C}$ for $16 \mathrm{~h}$ with trypsin at the ratio of enzyme-to-substrate of 1:40 (wt/wt). BSA (6.6 $\mathrm{mg}$ ) and ovalbumin (4 mg) were, respectively, dissolved in $1 \mathrm{~mL}$ denaturing buffer containing $8 \mathrm{M}$ 
urea and $50 \mathrm{mM}$ ammonium bicarbonate; after the addition of $20 \mu \mathrm{L}$ of DTT $(50 \mathrm{mM})$, the mixtures were incubated at $60^{\circ} \mathrm{C}$ for $1 \mathrm{~h}$ to reduce the disulfide bonds of proteins; subsequently, $40 \mu \mathrm{L}$ of IAA (50 mM) was added and the mixtures were then incubated at room temperature in dark for $30 \mathrm{~min}$; finally, the mixtures were diluted 10-fold with $50 \mathrm{mM}$ ammonium bicarbonate buffer ( $\mathrm{pH} 8.2)$ and digested at $37^{\circ} \mathrm{C}$ for $16 \mathrm{~h}$ with trypsin at the ratio of enzyme-to-substrate of 1:40 $(w t / w t)$. The proteins from the mouse liver were obtained according to the procedure described in a literature [4], and the Bradford protein assay was used to quantify the concentration of the extracted proteins. The tryptic digestion of the proteins from mice liver was as the same as that of BSA. All of the obtained proteolytic digests were stored in a $-30^{\circ} \mathrm{C}$ freezer before MALDI-TOF MS analysis.

\section{The Capture of Phosphopeptides Using $\mathrm{Zr}^{4+}-\mathrm{PO}_{3}{ }^{-}$ modified $\mathrm{Fe}_{3} \mathrm{O}_{4} / \mathrm{SiO}_{2}$ Magnetic Nanoparticles}

Protein digests were diluted with loading buffer $(\mathrm{pH}$ 0.85 ) containing $6 \%$ TFA and $80 \%$ (vol/vol) ACN. A protein digest solution ( $1 \mathrm{pmol}, 2 \mu \mathrm{L}$ ) was added into a $10 \mu \mathrm{L}$ suspension of $\mathrm{ZrPO}_{3}$-modified magnetic $\mathrm{Fe}_{3} \mathrm{O}_{4}$ nanoparticles $(15 \mathrm{mg} / \mathrm{mL})$ in loading buffer, and incubated at room temperature for $30 \mathrm{~min}$. After that, the magnetic nanoparticles were held by a magnet and the supernatant was removed by Eppendorf pipette, and then the magnetic nanoparticles were rinsed with $20 \mu \mathrm{L}$ of loading buffer solutions containing 6\% TFA and $80 \%$ (vol/vol) ACN with and without $200 \mathrm{mM} \mathrm{NaCl}$, respectively. After the evaporation of solvent, $5 \mu \mathrm{L}$ of 25 $\mathrm{mg} / \mathrm{mL} \mathrm{2,5-DHB}$ solution containing 70\% ACN and $1 \%$ $\mathrm{H}_{3} \mathrm{PO}_{4}$ were added and mixed homogeneously with these dried nanoparticles, where the addition of $\mathrm{H}_{3} \mathrm{PO}_{4}$ in matrix solution was for the enhancement of phosphopeptide signals on MALDI-TOF MS analysis [31]. Finally, a $0.5 \mu \mathrm{L}$ aliquot of the matrix-nanoparticle suspension was directly deposited on MALDI-target for MALDI-TOF MS analysis. For phosphoproteome analysis of mouse liver lysate, the magnetic nanoparticles $(100 \mu \mathrm{L}, 15 \mathrm{mg} / \mathrm{mL})$ were incubated with the tryptic digest of $200 \mu \mathrm{g}$ mouse liver lysate. Then the nanoparticles were rinsed with $200 \mu \mathrm{L}$ of loading buffer solutions containing $0.5 \%$ TFA and $80 \%$ (vol/vol) ACN with and without $200 \mathrm{mM} \mathrm{NaCl}$, respectively. Subsequently, the trapped phosphopeptides were eluted from the nanoparticles as followings: (1) by an $80 \%$ (vol/vol) ACN solution containing $6.0 \%$ TFA and with $10 \mathrm{~min}$ incubation, and (2) by an $\mathrm{NH}_{4} \mathrm{OH}$ solution ( $\mathrm{pH} 11.5,70$ $\mu \mathrm{L})$ with a 15 min sonication. By holding the magnetic nanoparticles with a magnetic field, the eluted supernatant was respectively collected, lyophilized, and then redissolved in $4 \mu \mathrm{L}$ of $0.1 \%$ formic acid for nano-LC-MS/MS and MS/MS/MS analysis.

\section{Mass Spectrometry}

All MALDI-TOF mass spectra were acquired by a Bruker Autoflex time-of-flight mass spectrometer (Bruker, Bremen, Germany) equipped with a delayed ion-extraction device and a 337-nm pulsed nitrogen laser. The MALDI uses a ground-steel sample target with 384 spots. The range of laser energy was adjusted to slightly above the threshold for obtaining good resolution and signal-to-noise ratio. All measurements were carried out in linear positive-ion mode with delayed ion extraction. The delay time for ion extraction and the extraction voltage were set at $90 \mathrm{~ns}$ and $20 \mathrm{kV}$, respectively. Each MS spectrum was acquired by the accumulation of 30 laser shots.

All nano-LC-MS analyses were performed on a ThermoFinnegan LTQ linear ion trap mass spectrometer with a nanospray ion source and a Surveyor HPLC system (ThermoFinnegan, San Jose, CA). The flow rate of HPLC pump was split to $200 \mathrm{~nL} / \mathrm{min}$ by a cross for capillary separation. A bare fused silica capillary (75 $\mu \mathrm{m}$ i.d. $\times 120 \mathrm{~mm}$ length) was manually pulled to form a MS emitter tip (ca. $5 \mu \mathrm{m}$ i.d.) at one end, and then was in-house packed with C18 AQ particles (5 $\mu \mathrm{m}, 120 \AA$; Michrom BioResources, Auburn, CA) using a pneumatic packing device. The packed capillary column was directly coupled to the LTQ mass spectrometer; $0.1 \%$ formic acid in $\mathrm{H}_{2} \mathrm{O}$ was used as the mobile phase $\mathrm{A}$, and $0.1 \%$ formic acid in acetonitrile was used as the mobile phase B. The LTQ mass spectrometer was operated at positive ion mode. A voltage of $1.8 \mathrm{kV}$ was applied to the cross. About $1 \mu \mathrm{L}(50 \mu \mathrm{g})$ of redissolved peptides was loaded onto a C18 capillary column as sample loop and separated on the capillary column with a linear gradient where the mobile phase $B$ was programmed from 5 to $35 \%$ in $75 \mathrm{~min}$. For the detection of phosphopeptides, the mass spectrometer was set to perform a full scan MS followed by three data-dependant MS/MS $\left(\mathrm{MS}^{2}\right)$. Subsequently, an MS/MS/MS $\left(\mathrm{MS}^{3}\right)$ (spectrum was automatically triggered when the most three intense peaks from the MS/MS spectrum corresponded to the neutral loss event of 98,49 , and $33 \pm 1$ Da for the precursor ion with $1+, 2+, 3+$ charge states, respectively.

\section{Database Search and Data Analysis}

The peak lists for $\mathrm{MS}^{2}$ and $\mathrm{MS}^{3}$ spectra were generated from the raw data by Bioworks (Thermo-Electron, Boston, MA) with parameters: mass range, 600 to 3500; intensity threshold, 1000; minimum ion count, 10. The $\mathrm{MS}^{2}$ and $\mathrm{MS}^{3}$ spectra were searched using SEQUEST [32] (version 2.7) against a composite database including both original database and the reversed version of the forward one with parameters: enzyme, trypsin (KR/P); enzyme limits, fully enzymatic (cleaves at both ends); precursor-ion mass tolerance, $2 \mathrm{Da}$; fragment-ion mass tolerance, $1 \mathrm{Da}$; missed cleavages, 2; static modification, Cys (+57). For search with $\mathrm{MS}^{2}$ data, the 
dynamic modifications were set for oxidized Met $(+16)$, and phosphorylated Ser, Thr, and Tyr $(+80)$. For search with $\mathrm{MS}^{3}$ data, besides the parameters for $\mathrm{MS}^{2}$, dynamic modifications were also set for water loss on Ser, Thr $(-18)$. The original database is the nonredundant mouse protein database of the International Protein Index (ipi.MOUSE.3.17.fasta), which includes 51,446 entries. For the identification of nonphosphopeptides by $\mathrm{MS}^{2}$, the criteria were set at: cross-correlation value (Xcorr) $\geq 1.9,2.2,3.75$ for single, double, triple charges, and Delta $\mathrm{Cn} \geq 0.1$ [33-35]. For the identification of phosphopeptides by matching the assigned sequences derived from $\mathrm{MS}^{2}$ and $\mathrm{MS}^{3}$ data, the homemade software named APIVASE [36] was used to validate the identification. With this software, the $\mathrm{MS}^{2}$ / $\mathrm{MS}^{3}$ target-decoy database search approach (or called $\mathrm{MS}^{2} / \mathrm{MS}^{3}$ approach in short) was applied to identify the most likely phosphorylation sites via following four steps: (1) extraction of the valid $\mathrm{MS}^{2} / \mathrm{MS}^{3}$ pairs by removal of the $\mathrm{MS}^{2} / \mathrm{MS}^{3}$ pairs with incorrect charge states, $\mathrm{MS}^{3}$ not triggered, and intensity of the peak corresponding to neutral loss less than $50 \%$ of the base peak in $\mathrm{MS}^{2}$; (2) performing $\mathrm{MS}^{2}$ and $\mathrm{MS}^{3}$ target-decoy database search with the valid $\mathrm{MS}^{2}$ and $\mathrm{MS}^{3}$ spectra, respectively; (3) reassignment of peptide scores in SEQUEST output to generate the peptide lists with the reassigned scores for $\mathrm{MS}^{2}$ and $\mathrm{MS}^{3}$; (4) filtering the candidate phosphopeptides with new defined parameters (Rank'm, DCn'm, and Xcorr's) to achieve phosphopeptide identification with specific FDR. In this study, to achieve the false discovery rate (FDR) of $1 \%$, the following filter criteria were used: Rank'm $=1$, $\mathrm{DCn}^{\prime} \mathrm{m} \geq 0.1$, and Xcorr's $\geq 0.5350$. The phosphoproteins identified by the same phosphopeptide(s) were grouped, if the group contained more than one phosphoprotein then only one was kept according to the method described by He et al. [37] as all proteins in each group are highly homologous, generally belonging to the same superfamily, or just different alternative splicing isoforms. Finally, to investigate the reliability of the peptide identification, the PhosphoSite (http: \\www. phosphosite.org) was used to distinguish the known from novel phosphorylation sites.

\section{Results and Discussion}

\section{Characteristics of $\mathrm{Zr}^{4+}-\mathrm{PO}_{3}$-Modified Magnetic $\mathrm{Fe}_{3} \mathrm{O}_{4} / \mathrm{SiO}_{2}$ (Core/Shell) Nanoparticles}

To demonstrate the preparation of the $\mathrm{Zr}^{4+}-\mathrm{PO}_{3}$-modified magnetic $\mathrm{Fe}_{3} \mathrm{O}_{4} / \mathrm{SiO}_{2}$ (core/shell) nanoparticles, a synthesis procedure is illustrated in Scheme 1. Briefly, the magnetic $\mathrm{Fe}_{3} \mathrm{O}_{4}$ nanoparticles were first prepared via a solvothermal method, and coated with a layer of $\mathrm{SiO}_{2}$ generated from the hydrolysis and condensation of TEOS. Subsequently, the surface silanol groups on the $\mathrm{SiO}_{2}$ layer were derivatized to aminopropyl groups by APTES and further transferred to phosphonate groups by $\mathrm{POCl}_{3}$. Lastly, after the reaction with $\mathrm{ZrOCl}_{2}$, the

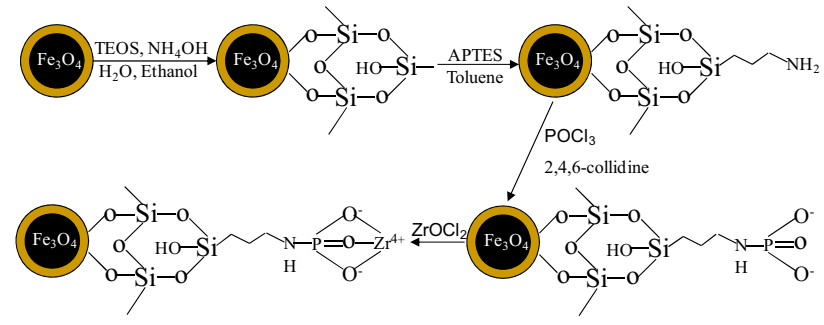

Scheme 1. Synthesis of $\mathrm{Zr}^{4+}-\mathrm{PO}_{3}$-modified magnetic nanoparticles. TEOS: tetraethoxysilane; APTES: 3-aminopropyl-triethoxysilane.

$\mathrm{Zr}^{4+}$ cations were immobilized on the phosphonated magnetic nanoparticles for selective capture of phosphopeptides from proteolytic digests due to the coordination of zirconium ion and the phosphate moieties from phosphopeptides. The TEM image (Supplementary Figure 1, which can be found in the electronic version of this article) of the $\mathrm{Zr}^{4+}-\mathrm{PO}_{3}$-modified magnetic nanoparticles was recorded at a high magnification for nanoparticle characterization. The scale bar represents $50 \mathrm{~nm}$. The obtained nanoparticles were aggregated, and the estimated average diameter of nanoparticles was $\sim 16 \mathrm{~nm}$.

\section{Enrichment of Phosphopeptides from Trypsin Digests of Standard Phosphoproteins}

To examine the specific selectivity of the prepared $\mathrm{Zr}^{4+}-\mathrm{PO}_{3}$-modified magnetic $\mathrm{Fe}_{3} \mathrm{O}_{4}$ nanoparticles for trapping phosphopeptides, the proteolytic digests of bovine $\beta$-casein that posses five known phosphorylation sites have been extensively selected as the test standard phosphoprotein with detection of MALDITOF mass spectrometry $[15,24,38]$. First, the tryptic digest of bovine $\beta$-casein ( 1 pmol) was incubated with certain amount $(150 \mu \mathrm{g})$ of $\mathrm{Zr}^{4+}-\mathrm{PO}_{3}$-modified magnetic $\mathrm{Fe}_{3} \mathrm{O}_{4}$ nanoparticles at room-temperature for $30 \mathrm{~min}$. By holding the magnetic nanoparticles with a magnet, the supernatant was removed by a pipette. Followed by a series of rinsing steps for removing nonphosphorylated peptides and salts from the nanoparticles, the MALDI matrix of 2,5-DHB was added and mixed with the peptide-bound magnetic nanoparticles and deposited on MALDI target for mass spectrometry analysis. For comparison, the same amount of the tryptic digest of $\beta$-casein ( 1 pmol) was directly analyzed by MALDITOF MS without the trapping steps by $\mathrm{Zr}^{4+}-\mathrm{PO}_{3^{-}}$ magnetic nanoparticles. Figure 1a represents the direct MALDI-TOF mass spectrum of the tryptic digest of $\beta$-casein (1 pmol) without the treatment of the nanoparticles, while Figure $1 \mathrm{~b}$ represents the obtained MALDITOF mass spectrum of the tryptic digest of the same amount of $\beta$-casein ( $1 \mathrm{pmol}$ ) after treated by $\mathrm{Zr}^{4+}-\mathrm{PO}_{3^{-}}$ magnetic nanoparticles. In Figure $1 \mathrm{a}$, the peaks of the nonphosphorylated peptides and phosphorylated peptides arising from the tryptic digest of $\beta$-casein were all 


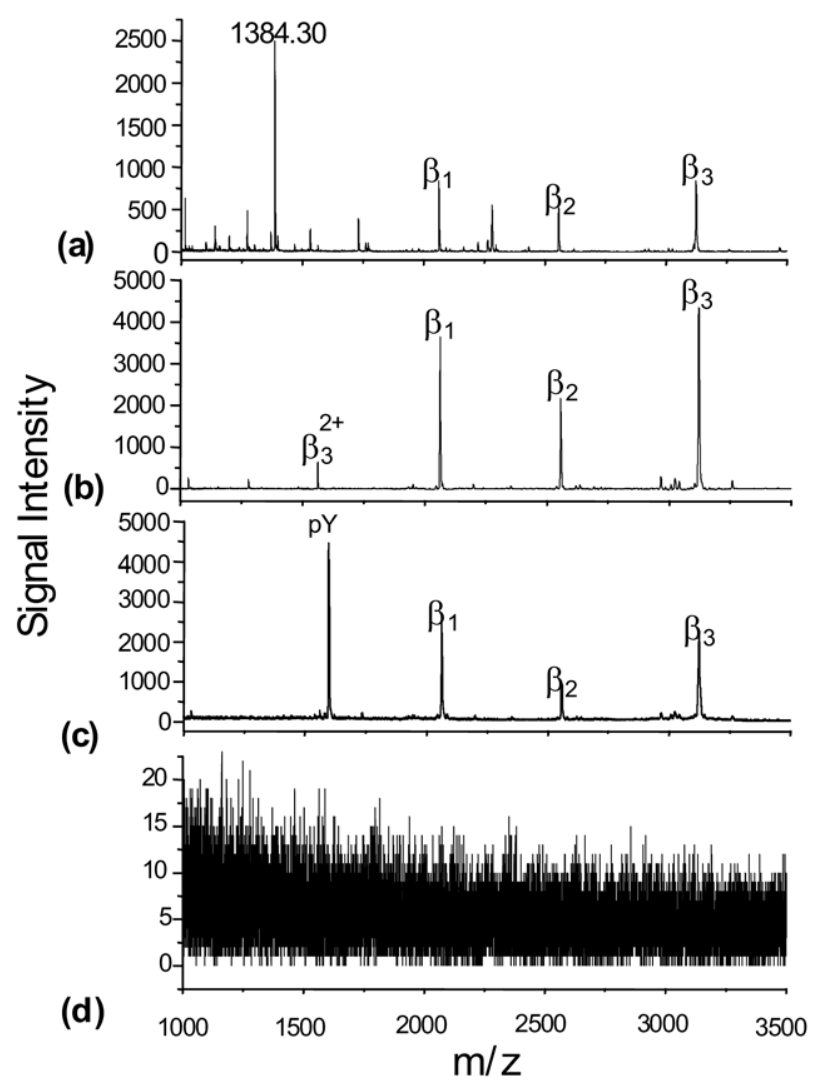

Figure 1. MALDI-TOF-MS analysis of tryptic digests of (a) $\beta$-casein (1 pmol, $2 \mu \mathrm{L}$ ) by direct analysis; (b) $\beta$-casein (1 pmol, $2 \mu \mathrm{L}$ ) treated by $\mathrm{Zr}^{4+}-\mathrm{PO}_{3}$-modified magnetic nanoparticles; (c) $\beta$-casein (1 pmol, $2 \mu \mathrm{L})$ mixed with standard phosphotyrosine (pY) at ratio of $1: 1$ and subsequently treated by $\mathrm{Zr}^{4+}-\mathrm{PO}_{3}$-modified magnetic nanoparticles; (d) analysis of $\beta$ casein $(1 \mathrm{pmol}, 2 \mu \mathrm{L})$ treated by $\mathrm{PO}_{3}$-magnetic nanoparticle.

detected in the direct MALDI MS analysis manner, where the phosphorylated peptides were marked as $\beta_{1}$, $\beta_{2}$, and $\beta_{3}$ at $\mathrm{m} / \mathrm{z} 2061.94,2556.93$, and 3122.56, respectively; however, the nonphosphorylated peptide peak at 1384.30 dominates the mass spectrum and lots of nonphosphopeptides appear in the mass spectrum. In contrast, Figure $1 \mathrm{~b}$ shows a much clearer mass spectrometric pattern with only four phosphopeptide peaks from the tryptic digest of $\beta$-casein after the specific capture by $\mathrm{Zr}^{4+}-\mathrm{PO}_{3}$-magnetic nanoparticles. The identified phosphopeptides in amino acid sequence pattern were listed in Table 1. One (S50) of the five known phosphorylation sites (S30, S32, S33, S34, and S50) of bovine $\beta$-casein was founded in both phosphopeptides of $\beta_{1}(48-\mathrm{FQ}[\mathrm{P} S]$ EEQQQTEDELQK-63, $\mathrm{m} / \mathrm{z} 2061.94)$ and $\beta_{2}$ (48-FQ[PS]EEQQQTEDELQDKIHPF-67, $m / z$ 2556.93). Other four phosphorylation sites of bovine $\beta$-casein were identified in phosphopeptide $\beta_{3}$ (16-RELEELNVPGEIVE[ $\left.\left.\left.{ }_{\mathrm{P}} \mathrm{S}\right] \mathrm{L}{ }_{\mathrm{P}} \mathrm{S}\right] \mathrm{C}_{\mathrm{P}} \mathrm{S}\right]\left[{ }_{\mathrm{P}} \mathrm{S}\right] \mathrm{EESITR}-40, \mathrm{~m} / \mathrm{z}$ 3122.56). And $\beta_{3}^{2+}$ represents the doubly charged ion derived from $\beta_{3}$. As can be seen in Figure 1b, the peak intensities of these isolated phosphorylated peptides were significantly enhanced $\sim 5$-fold. This is because of the elimination of ion suppression from nonphosphorylated peptides and salts after the selective capture of phosphopeptides using the $\mathrm{Zr}^{4+}-\mathrm{PO}_{3}$-modified magnetic nanoparticles. Two other standard phosphoproteins ( $\alpha$-casein and ovalbumin) were also used to examine the selectivity of $\mathrm{Zr}^{4+}-\mathrm{PO}_{3}$-modified magnetic nanoparticles; the identified phosphopeptides are listed in Table 1 . These results indicate that the $\mathrm{Zr}^{4+}-\mathrm{PO}_{3}$-modified magnetic nanoparticles have the specific selectivity for capturing phosphopeptides and thus as the promising substrate for isolation of phosphorylated peptides from a proteolytic digest mixture to increase the detection sensitivity of phosphopeptides with the detection of MALDI-TOF MS.

The above used phosphoproteins of $\alpha$-casein and $\beta$-casein all possess phosphorylation sites at serine residues. To evaluate the capture performance of $\mathrm{Zr}^{4+}$ $\mathrm{PO}_{3}$-modified magnetic nanoparticles towards other peptides phosphorylated at different amino acid residues, a singly tyrosine phosphorylated peptide of RRLIEDAE[ $\left.{ }_{\mathrm{P}} \mathrm{Y}\right] A A R G$ (where $\mathrm{pY}$ represents phosphotyrosine; molecule weight, 1599) was added to a tryptic digest of $\beta$-casein at a 1:1 $\mathrm{M}$ ratio, and followed by a trapping process of phosphopeptides by $\mathrm{Zr}^{4+}-\mathrm{PO}_{3^{-}}$ modified magnetic nanoparticles and the analysis of MALDI-TOF MS. As shown in Figure 1c, four dominant peaks representing three phosphoserine peptides from $\beta$-casein $\left(\beta_{1}, \beta_{2}, \beta_{3}\right)$ and one phosphotyrosine peptide $(\mathrm{pY})$ can be clearly observed. This result indicated that $\mathrm{Zr}^{4+}-\mathrm{PO}_{3}$-modified magnetic nanoparticles do posses the promising ability to selectively trap other types of phosphopeptides without bias.

To further confirm the interacting moiety of the prepared $\mathrm{Zr}^{4+}-\mathrm{PO}_{3}$-magnetic nanoparticles for selectively isolating phosphopeptides, the tryptic digest of $\beta$-casein $(1 \mathrm{pmol})$ were also analyzed by MALDI-TOF mass spectrometry by using $\mathrm{PO}_{3}$-modified magnetic nanoparticles without loading of zirconium cations. Figure $1 \mathrm{~d}$ represents the obtained MALDI mass spectrum of the tryptic digest of $\beta$-casein using the $\mathrm{PO}_{3}$ modified magnetic nanoparticle instead of the $\mathrm{Zr}^{4+}$ $\mathrm{PO}_{3}$-modified magnetic nanoparticles. As expected, no any peaks representing the phosphorylated peptides from $\beta$-casein was observed. Based on this result, it can be confirmed that the selective capture of phosphopeptides is from the strong specific interaction between the immobilized zirconium cations and the phosphoryl groups of phosphopeptides.

Inspired by the satisfactory enrichment of phosphopeptides derived from $\beta$-casein, we further applied the $\mathrm{Zr}^{4+}-\mathrm{PO}_{3}$-modified magnetic nanoparticles on the selective capture of phosphopeptides from the proteolytic digest of ovalbumin, a diphosphorylated protein containing a disulfide bond. For ovalbumin, the addition of urea, DTT, and IAA are necessary for denaturing, opening disulfide bond and carbamidomethylating cysteine groups before tryptic digestion. It is of interest to investigate the impacts of urea, DTT, and IAA for tryptic digestion on the selective capture of phos- 
Table 1. Identification of phosphopeptides from $\alpha$-casein, $\beta$-casein and ovalbumin tryptic digests by using $\mathrm{Zr}^{4+}-\mathrm{PO}_{3}$-modified magnetic $\mathrm{Fe}_{3} \mathrm{O}_{4}$ nanoparticles as affinity probes in MALDI-TOF MS analysis

\begin{tabular}{|c|c|c|c|c|}
\hline Protein & No. & Amino acid sequence ${ }^{a}$ & $\begin{array}{l}\text { Number of phosphoryl } \\
\text { groups }\end{array}$ & Measured $\mathrm{m} / \mathrm{z}$ \\
\hline \multirow[t]{21}{*}{$\alpha$-Casein } & $\alpha_{1}$ & TVDME[P $\left.{ }_{P} S\right] T E V F$ & 1 & 1237.08 \\
\hline & $\alpha_{2}$ & TVD[Mo]ME[P $\left.{ }_{\mathrm{P}} \mathrm{S}\right] \mathrm{TEVF}^{\mathrm{b}}$ & 1 & 1253.11 \\
\hline & $\alpha_{3}$ & EQL $\left.\left.{ }_{p} S\right] T{ }_{P} S\right] E E N S K$ & 2 & 1411.90 \\
\hline & $\alpha_{4}$ & TVDME $\left.{ }_{\mathrm{P}} \mathrm{S}\right] \mathrm{TEVFTK}$ & 1 & 1466.97 \\
\hline & $\alpha_{5}$ & TVD[Mo]E[PS]TEVFTK ${ }^{\mathrm{b}}$ & 1 & 1482.61 \\
\hline & $\alpha_{6}$ & EQL[$\left.{ }_{p} S\right] T\left[{ }_{P} S\right]$ EENSKK & 2 & 1538.31 \\
\hline & $\alpha_{7}$ & VPQLEIVPN[PS]AEER & 1 & 1660.15 \\
\hline & $\alpha_{8}$ & YLGEYLIVPN [PS]AEER & 1 & 1832.70 \\
\hline & $\alpha_{9}$ & DIGSE[PS]TEDQAMEDIK & 1 & 1847.95 \\
\hline & $\alpha_{10}$ & 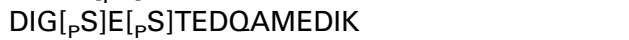 & 2 & 1927.89 \\
\hline & $\alpha_{11}$ & 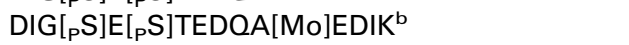 & 2 & 1943.89 \\
\hline & $\alpha_{12}$ & YKVPQLEIVPN[PS]AEER & 1 & 1951.09 \\
\hline & $\alpha_{13}$ & KKYKVPQLEIVPN[PS]AEERL & 1 & 2080.00 \\
\hline & $\alpha_{14}$ & NTMEHV $\left.{ }_{P} S\right]\left[_{P} S\right]\left[{ }_{P} S\right] E E S I I\left[{ }_{P} S\right] Q E T Y K$ & 4 & 2618.93 \\
\hline & $\alpha_{15}$ & VNEL[$\left.{ }_{P} S\right] K D I G\left[{ }_{P} S\right] E\left[_{P} S\right]$ TEDQAMEDIK & 3 & 2678.02 \\
\hline & $\alpha_{16}$ & $Q^{*} \operatorname{MEAE}\left[{ }_{P} S\right] I\left[{ }_{P} S\right]\left[{ }_{P} S\right]\left[{ }_{P} S\right]$ EEIVPN $\left[{ }_{P} S\right] V E A Q K^{c}$ & 5 & 2703.75 \\
\hline & $\alpha_{17}$ & QMEAE $\left[{ }_{P} S\right] I\left[{ }_{P} S\right]\left[{ }_{P} S\right]\left[{ }_{P} S\right]$ EEIVPNPN [ $\left.{ }_{P} S\right] V E O K$ & 5 & 2720.05 \\
\hline & $\alpha_{18}$ & KEKVNEL[ $\left.\left.{ }_{P} S\right] K D I G{ }_{P} S\right]$ E[P $\left.{ }_{P} S\right]$ TEDOAMEDIKO & 3 & 2935.87 \\
\hline & $\alpha_{19}$ & NANEEEYSIG $\left[{ }_{P} S\right]\left[\left[_{P} S\right]\left[_{P} S\right] E E\left[_{P} S\right] A E V A T E E V K\right.$ & 4 & 3008.22 \\
\hline & $\alpha_{20}$ & NANEEEY $\left[{ }_{P} S\right] I G\left[{ }_{P} S\right]\left[{ }_{P} S\right]\left[{ }_{P} S\right]$ EE $\left[{ }_{P} S\right] A E V A T E E V K$ & 5 & 3087.93 \\
\hline & $\alpha_{21}$ & KNTMEHV[P $\mathrm{P}]\left[_{\mathrm{P}} \mathrm{S}\right]\left[_{\mathrm{P}} \mathrm{S}\right] \mathrm{EE}\left[_{\mathrm{P}} \mathrm{S}\right]$ IISOETYKOEK & 4 & 3132.23 \\
\hline \multirow[t]{3}{*}{$\beta$-Casein } & $\beta_{1}$ & FQ[ $\left.{ }_{\mathrm{P}} \mathrm{S}\right] \mathrm{EEQOOTEDELODK}$ & 1 & 2061.94 \\
\hline & $\beta_{2}$ & FQ[PS]EEQQQTEDELQDKIHPF & 1 & 2556.93 \\
\hline & $\beta_{3}$ & RELEELNVPGEIVE $\left[{ }_{P} S\right] L\left[{ }_{P} S\right]\left[{ }_{p} S\right]\left[{ }_{P} S\right] E E S I T R$ & 4 & 3122.56 \\
\hline \multirow[t]{2}{*}{ Ovalbumin } & $\mathrm{O}_{1}$ & EVVG $\left.{ }_{P} S\right] A E A G V D A A S V S E E F R$ & 1 & 2090.62 \\
\hline & $\mathrm{O}_{2}$ & FDKLPGFGD[ ${ }_{P} S$ ]IEAOCGTSVNVHSSLR & 1 & 2903.46 \\
\hline
\end{tabular}

pS: phosphorylated site.

a The amino acid sequence are cited from Larsen et al. [15] and Kweon et al. [16].

${ }^{b}$ Oxidation on methionine.

cPyroglutamylation on the $\mathrm{N}$-terminal $\mathrm{Q}^{*}$.

phopeptides by $\mathrm{Zr}^{4+}-\mathrm{PO}_{3}$-modified magnetic nanoparticles. Figure $2 \mathrm{a}$ and $\mathrm{b}$, represent MALDI mass spectra of the tryptic digest of ovalbumin $(1$ pmol, $2 \mu \mathrm{L})$ before and after phosphopeptide captured by $\mathrm{Zr}^{4+}$ $\mathrm{PO}_{3}$-modified magnetic nanoparticles. By comparing Fig. $2 \mathrm{a}$ and $\mathrm{b}$, it clearly shows that the phosphopeptides

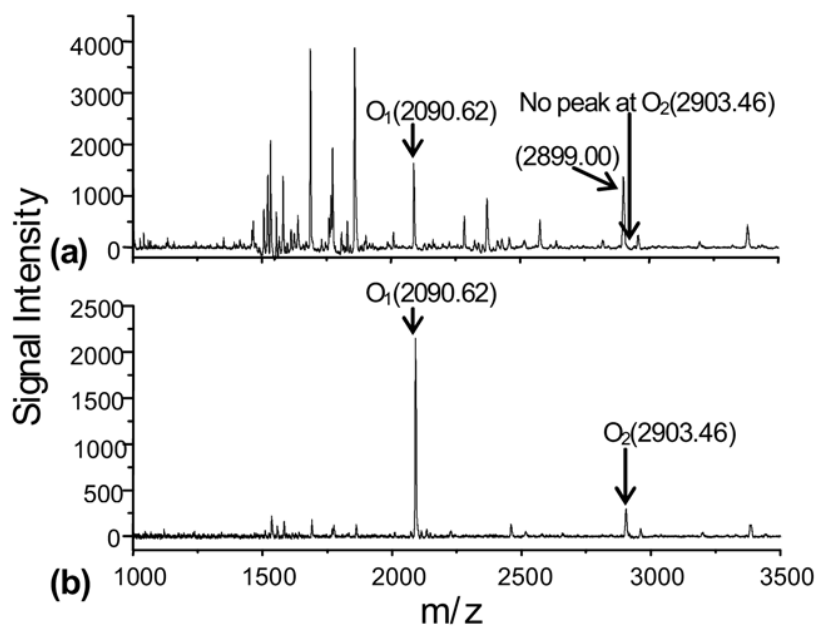

Figure 2. MALDI-TOF mass spectra of a tryptic digest of ovalbumin $(1$ pmol, $2 \mu \mathrm{L})(\mathbf{a})$ by direct analysis; (b) treated by $\mathrm{Zr}^{4+}-\mathrm{PO}_{3}^{-}$ modified magnetic nanoparticles. at $\mathrm{m} / \mathrm{z} 2090.62$ and 2903.46 can be distinctly isolated from the strong background of nonphosphopeptides without the loss of peak intensity by $\mathrm{Zr}^{4+}-\mathrm{PO}_{3}$-modified magnetic nanoparticles. The amino acid sequences of detected phosphopeptides of ovalbumin with marked phosphorylation sites are illustrated in Table 1. It can be concluded that the use of urea, DTT, and IAA for tryptic digestion will not impact the specific capture of phosphopeptides with $\mathrm{Zr}^{4+}-\mathrm{PO}_{3}$-modified magnetic nanoparticles. This is a very interesting merit for using $\mathrm{Zr}^{4+}-\mathrm{PO}_{3}$-modified magnetic nanoparticles because the denaturing processes are routinely applied in proteome analysis.

\section{Effects of Incubation Conditions on Capture of Phosphopeptide}

To evaluate the effect of the amount of $\mathrm{Zr}^{4+}-\mathrm{PO}_{3}$ modified magnetic nanoparticles on the specific capture of phosphopeptides, the $\mathrm{Zr}^{4+}-\mathrm{PO}_{3}$-modified magnetic nanoparticle suspensions at different concentrations with a certain volume were used for isolating phosphopeptides and followed by the detection of MALDITOF MS. Figure 3 shows the peak intensities of the isolated phosphorylated peptides from the tryptic digests of $\beta$-casein $(1 \mathrm{pmol})$ at the different ratios of 


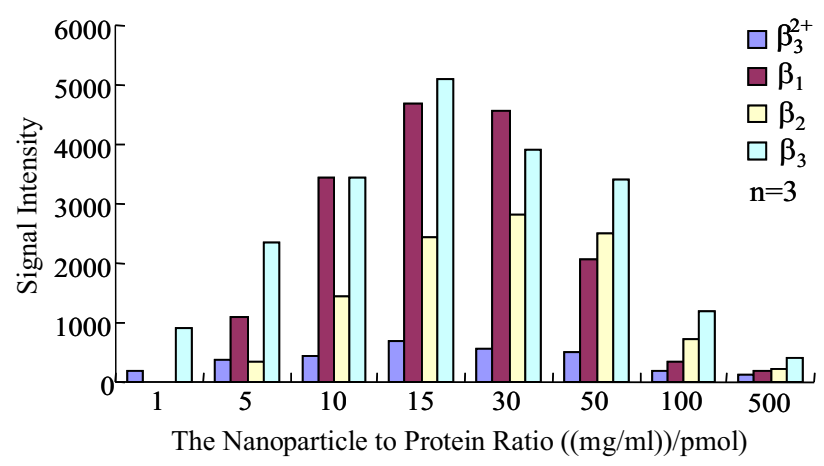

Figure 3. The effect of the ratio of nanoparticle-to-protein ([mg/ $\mathrm{mL}] / \mathrm{pmol}$ ) on signal intensities (averaged, $n=3$ ) of phosphopeptides from a tryptic digest of $\beta$-casein (1 pmol, $2 \mu \mathrm{L}$ ).

nanoparticle-to-protein $(\mathrm{mg} / \mathrm{mL}$ of nanoparticle versus pmol of protein) ranged from 1:1 to 500:1. As shown in Figure 3, at low ratio of nanoparticle-to-protein of 1:1, only two dominant peaks $\left(\beta_{3}\right.$ and $\left.\beta_{3}^{2+}\right)$ representing multiphosphopeptides from the tryptic digest of $\beta$-casein can be observed, whereas other monophosphopeptides in the tryptic digest could not be detected, possibly due to stronger chelating interaction between multiphosphopeptide and $\mathrm{Zr}^{4+}$ cations on nanoparticles than that for monophosphopeptides, which resulted in the competitive occupation of the $\mathrm{Zr}^{4+}$ sites by multiphosphopeptides. When the ratio increased to $5: 1$, the other two peaks $\left(\beta_{1}\right.$ and $\left.\beta_{2}\right)$ of monophosphopeptides were then observed as well as the increase of the peak intensity of $\beta_{3}$ and $\beta_{3}^{2+}$. By further increasing the ratio to $10: 1,15: 1$, the intensities of detectable peaks of phosphopeptides were also increased, and $\beta_{3}^{2+}, \beta_{1}$, and $\beta_{3}$ reached the summit at the ratio of 15:1 with the expected highest capacity for phosphopeptides enrichment. After this summit, the peak intensities of $\beta_{3}^{2+}, \beta_{1}$, and $\beta_{3}$ started to decline when the ratio increased to $30: 1$, while the peak intensity of the monophosphopeptides of $\beta_{2}$ increased to the summit. Interestingly, when the ratio kept on increasing to 100:1 and 500:1, the peak intensities of phosphopeptides then declined. This phenomenon clearly indicated that the phosphopeptides in digestion solution have not been maximally adsorbed when the ratio of 15:1 of nanoparticle-to-protein was less than 15:1. So, the more nanoparticles used, the more phosphopeptides were adsorbed onto the nanoparticles, and the peak intensities of phosphopeptides were thus proportionally increased in MALDI-TOF MS. However, after the ratio of 15:1, the more nanoparticles used would result in the decrease of the specific concentrations of the phosphopeptides adsorbed on the surface of the nanoparticles and consequently caused the decrease of the peak intensities of the phosphopeptides. Based on the above observation, the ratio of nanoparticle-to-protein of 15:1 was selected to capture phosphopeptides from tryptic digests, which corresponded to the concentration of nanoparticle suspension of $15 \mathrm{mg} / \mathrm{mL}$ for final use.
Besides the selection of the ratio of nanoparticle-toprotein, the incubation time for phosphopeptides enrichment was also examined. Figure 4 displays the MALDI mass spectra of the phosphopeptides isolated by $\mathrm{Zr}^{4+}-\mathrm{PO}_{3}$-modified magnetic nanoparticles with different incubation time ranged from $0.5 \mathrm{~min}$ to $60 \mathrm{~min}$. As seen in Figure 4, four intensive phosphopeptide peaks can be observed even the incubation time is only $0.5 \mathrm{~min}$, when the incubation process remained longer than $30 \mathrm{~min}$, the best peak intensity could be achieved, it can be assumed that the chelating interaction between the zirconium cations and the phosphoryl groups of phosphopeptides have achieved equilibrium. These results indicated that the affinity nanoparticles have the good selectivity to capture phosphopeptides even in short interacting time. For obtaining better analysis results of phosphopeptides, incubation time of $30 \mathrm{~min}$ was selected.

\section{Detection Sensitivity for Phosphopeptides Using $\mathrm{Zr}^{4+}-\mathrm{PO}_{3}$-Magnetic Nanoparticles}

After going through the same trapping procedure by using $\mathrm{Zr}^{4+}-\mathrm{PO}_{3}$-modified magnetic nanoparticles as the affinity probes to phosphopeptides with MALDI-TOF MS analysis, the detection sensitivity of phosphopeptides on this approach was evaluated by using $5 \mathrm{fmol}$ and $0.5 \mathrm{fmol}$ of $\beta$-casein with the ratio of nanoparticleto-protein at $15: 1$ and the incubation time at $30 \mathrm{~min}$. The resulting MALDI-TOF mass spectra for $5 \mathrm{fmol}$ and 0.5 fmol of $\beta$-casein were shown in Figure $5 a$ and $b$, respectively. It can be seen that the three phosphopeptide peaks of $\beta_{1}, \beta_{2}$, and $\beta_{3}$ were well detected at these low femtomole levels by mass spectrometry after the enrichment of nanoparticles. The signal-to-noise $(\mathrm{S} / \mathrm{N})$ of detected phosphopeptides of $\beta_{1}, \beta_{2}$, and $\beta_{3}$ derived from $5 \mathrm{fmol} \beta$-casein were 16,6 , and 7 , respectively. For even lower level of $0.5 \mathrm{fmol} \beta$-casein, these three $\beta_{1}, \beta_{2}$, and $\beta_{3}$ phosphopeptides peaks were still able to be detected with $\mathrm{S} / \mathrm{N}$ of ca. 3 . This low fmol level was considered as the detection limit of this approach for

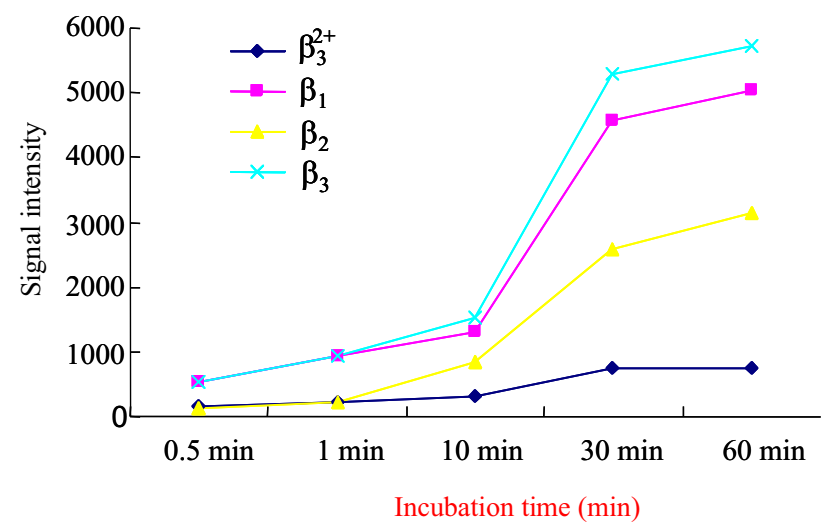

Figure 4. The effect of the incubation time on peak intensities of phosphopeptides captured by $\mathrm{Zr}^{4+}-\mathrm{PO}-{ }_{3}$-magnetic $\mathrm{Fe}_{3} \mathrm{O}_{4} / \mathrm{SiO}_{2}$ nanoparticles from a tryptic digest of $\beta$-casein $(1 \mathrm{pmol}, 2 \mu \mathrm{L})$. 


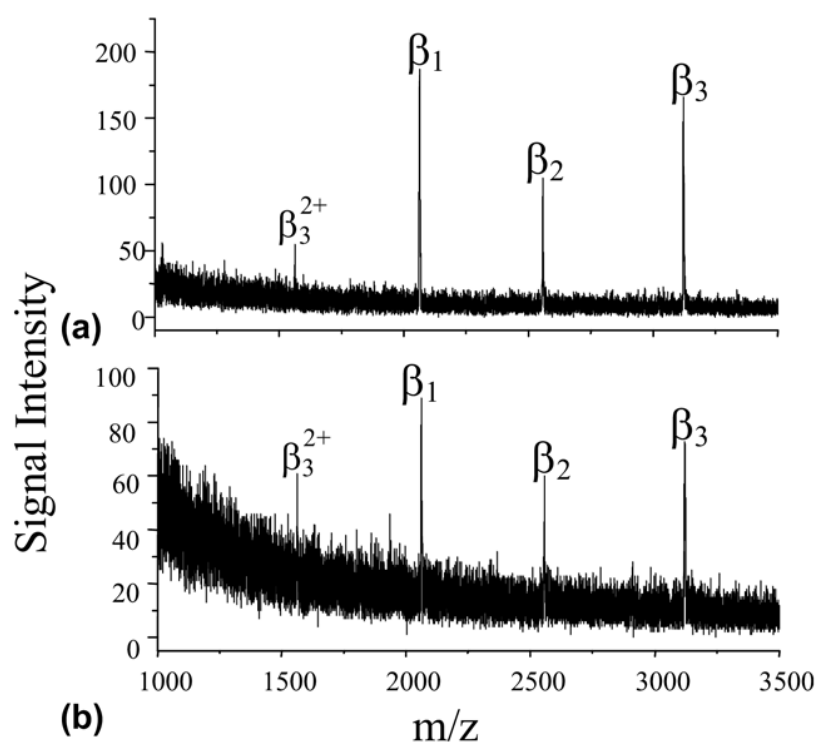

Figure 5. MALDI-TOF mass spectra of a tryptic digest of $\beta$ casein of (a) $5 \mathrm{fmol}, 6 \mu \mathrm{L}$; and (b) $0.5 \mathrm{fmol}, 8 \mu \mathrm{L}$, treated by $\mathrm{Zr}^{4+}-\mathrm{PO}_{3}$-magnetic $\mathrm{Fe}_{3} \mathrm{O}_{4} / \mathrm{SiO}_{2}$ nanoparticles, respectively.

detecting phosphopeptides, which is lower than that of other approaches by using $\mathrm{TiO}_{2}$ beads, $\mathrm{ZrO}_{2}$ beads and $\mathrm{Fe}^{3+}$-immobilized affinity chromatography as the affinity probes in conjunction with MALDI-TOF MS analysis $[15,17,18,31]$. The lower limit of detection for phosphopeptide could be attributed to large surface-tovolume ratio of the magnetic nanoparticle, which results in the high loading capacity of $\mathrm{Zr}^{4+}$ cations and consequently large trapping capacity towards phosphopeptides of proteolytic digests.

\section{Validating the Selective Capture of Phosphopeptides from Other Proteolytic Digests}

Phosphoproteins are typically at low abundance in real biological proteins samples. The specific isolation of phosphopeptides with the interference of a large amount of nonphosphorylated peptides is an important technique for phosphoproteome analysis. However, $\mathrm{Fe}^{3+}$-IMAC adsorbents showed not enough specificity for selective capture of phosphopeptides from a complex peptides mixture. Using $\mathrm{Fe}^{3+}$-IMAC to capture phosphopeptides, Larsen et al. [15] found that the number of nonphosphopeptide peaks increased significantly, while the number of detected phosphopeptides decreased dramatically when the ratio of phosphoproteins ( $\alpha$-casein, $\beta$-casein, and ovalbumin) to nonphosphoproteins (serum albumin, $\beta$-lactoglobulin, and carbonic anhydrase) in a protein sample decreased to 1:10; and when the ratio further decreased to 1:50, the peaks of phosphopeptides could hardly be detected. This phenomenon was also observed by Zhou et al. [39]. To examine the performance of $\mathrm{Zr}^{4+}-\mathrm{PO}_{3}$-modified magnetic nanoparticles for selective capturing phosphopeptides from a complex protein sample, the mixture of standard proteins of $\alpha$-casein and BSA was used. Figure 6 displays the obtained MALDI mass spectra of captured phosphopeptides from the tryptic digest of the mixture with different molar ratios of 1:0, 1:10, and 1:100 of $\alpha$-casein to BSA. In Figure 6a, many nonphosphopeptides were observed in mass spectrum. However, in Figure 6c, 20 phosphopeptides including mono- and multiphosphorylated peptides were clearly detected at the molar ratio of $\alpha$-casein to BSA of 1:10. Although the peak intensities of phosphopeptides were decreased due to the increased interference from nonphosphorylated peptides at higher ratio of protein-to-BSA, this result is still as good as that of $\alpha$-casein without mixed with BSA, as shown in Figure 6b, where 21 phosphopeptides were observed. The identified phosphopeptides from $\alpha$-casein, including amino acid sequence and phosphorylation sites, are listed in Table 1. By further decreasing the molar ratio to $1: 100,17$ phosphopeptides still could be detected with the similar peak pattern of phosphopeptides with the disappearance of three phosphopeptide the peaks at $\mathrm{m} / \mathrm{z} 1411.90$, 1538.31, and 2678.02 as shown in Figure 6d. But, considering the level of $\alpha$-casein is two orders of magnitude lower than that of BSA in sample, the specificity of $\mathrm{Zr}^{4+}-\mathrm{PO}_{3}$-modified magnetic nanoparticles is good enough for the selective capture of phosphopeptides. This could be contributed by the enhanced surface area of nanoparticles with the increased loading capacity of $\mathrm{Zr}^{4+}$ cations for binding phosphopeptides.

\section{Application of $\mathrm{Zr}^{4+}-\mathrm{PO}_{3}$-Magnetic Nanoparticles for Phosphoproteome Analysis of Mouse Liver}

To further evaluate the performance for selective capture of phosphopeptides in real complex biological samples, $\mathrm{Zr}^{4+}-\mathrm{PO}_{3}$-magnetic nanoparticles were also applied to analyze the phosphoproteome of moue liver. Based on a further investigation on the effect of TFA content in washing solution, we found that some phosphopeptides could be lost when 6\% TFA was used in washing step, which could be avoided by using a washing solution containing lower TFA content of $0.5 \%$ (see Supplementary Figure 2). Thus, a two-step elution protocol was applied for eluting the phosphopeptides from nanoparticles based on the pre-removal of nonphosphopeptides by the loading solution containing $0.5 \%$ TFA. Namely, the eluents were collected by rinsing the nanoparticles with the $80 \%$ acetonitrile solution containing $6 \%$ TFA (first eluting step) and the $\mathrm{NH}_{4} \mathrm{OH}$ solution (second eluting step), respectively. Then, both collected eluents were analyzed by nano-LC-MS/MS and MS/MS/MS, respectively, as described in the Experimental section. The $\mathrm{MS}^{2}$ and $\mathrm{MS}^{3}$ spectra obtained were searched against database following the procedures described in the Experimental section, and an automatic validation approach, i.e., $\mathrm{MS}^{2} / \mathrm{MS}^{3}$ approach [36] was used to process these data. Phosphopeptide identification by matching the assigned sequences de- 


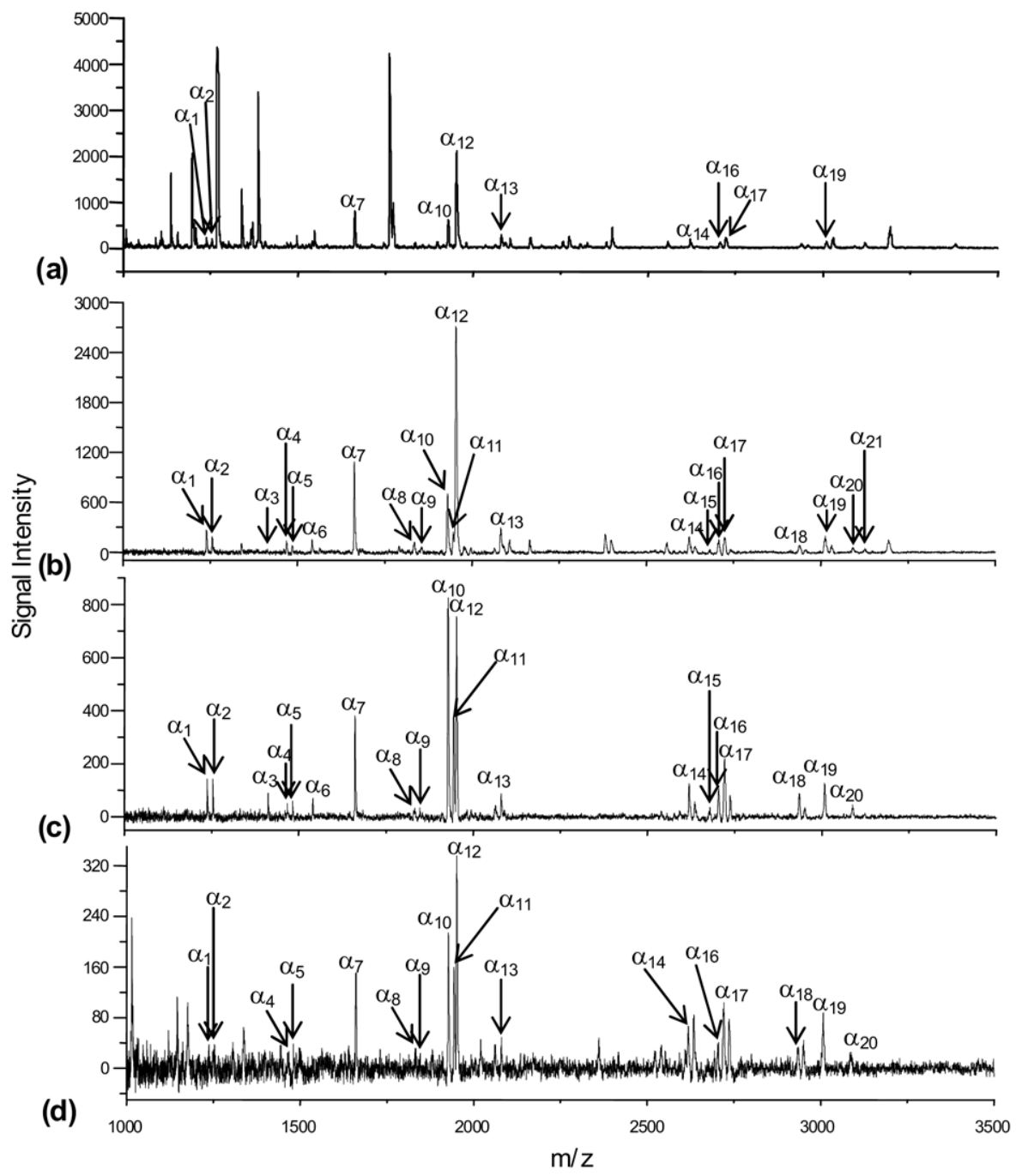

Figure 6. MALDI-TOF mass spectra of (a) $\alpha$-casein tryptic digest $(1 \mathrm{pmol}, 2 \mu \mathrm{L})$ by direct analysis; the mixtures of $\alpha$-casein $(1 \mathrm{pmol}, 2 \mu \mathrm{L})$ and BSA at ratios of (b) 1:0, (c) 1:10, and (d) 1:100, respectively, treated by $\mathrm{Zr}^{4+}-\mathrm{PO}_{3}$-modified magnetic nanoparticles.

rived from $\mathrm{MS}^{2}$ and $\mathrm{MS}^{3}$ data were described in the Experimental section. As a result, the total of 397 unique peptides including 203 nonphosphorylated peptides and 194 phosphorylated peptides were successfully identified. Among the 194 unique phosphorylated peptides, 39 (29 singly phosphorylated and 10 multi phosphorylated) were identified in the first eluting step and 155 (21 singly phosphorylated and 134 multi phosphorylated) were identified in the second eluting step, by the automatic validation approach. The sequences of the identified phosphopeptides and their Xcorr scores are listed in Supplemental Table 1. The majority of these peptides have very high Xcorr scores. In the first eluting step, the monophosphopeptides constitute $74.36 \%$ of all identified phosphopeptides, whereas they accounted for only $13.54 \%$ in the second eluting step. This might be ascribed to that fact the monophosphorylated peptides are supposed to have lower binding affinities with $\mathrm{Zr}^{4+}-\mathrm{PO}_{3}$-magnetic nanoparticles, and nearly eluted by loading solution containing 6\% TFA. On the other hand, the multiphosphorylated peptides had higher binding affinities and were eluted in the second step by the solution of $\mathrm{NH}_{4} \mathrm{OH}$, which is beneficial to the analysis of multiphosphorylated peptides by MS spectrometry because they could be easily suppressed by the presence of singly phosphorylated peptides owing to their poorer ionization efficiency.

Finally, to investigate the reliability of the results, PhosphoSite (http: \\www.phosphosite.org) was further used to distinguish the known from novel phosphorylation sites for the mouse liver lysate. For the 194 identified phosphorylated peptides with 318 phosphorylated sites, it was found $88.99 \%$ (283 sites) were identified as the known phosphorylation sites (see Supplemental Table 1). These results indicated the phosphopeptides identified both by $\mathrm{MS}^{2}$ and $\mathrm{MS}^{3}$ spectra are of high confidence. These results also showed that the $\mathrm{Zr}^{4+}-\mathrm{PO}_{3}$ - magnetic nanoparticles do have high specificity for the capture of phosphopeptides in real complex biological samples and are of very promising 
in the purification of phosphopeptides for phosphoproteome analysis.

\section{Conclusions}

In this work, the zirconium phosphonate-modified magnetic $\mathrm{Fe}_{3} \mathrm{O}_{4} / \mathrm{SiO}_{2}$ (core/shell) nanoparticles have been successfully prepared and applied as the affinity probes for the specific capture of phosphopeptides from complex tryptic digests with the detection of MALDITOF mass spectrometry. The affinity interactions between the zirconium phosphonate-modified magnetic nanoparticles and the phosphopeptides resulted from the strong chelating interactions between the zirconium cations and the phosphoryl groups of phosphopeptides. The specificity of the $\mathrm{Zr}^{4+}-\mathrm{PO}_{3}$ - magnetic nanoparticles has been confirmed by the selective capture of phosphopeptides from the tryptic digests of standard phosphoproteins, and the mixture of standard protein with BSA at the molar ratio of standard protein-to-BSA up to 1:100. The performance of the magnetic nanoparticles was also investigated by applying the nanoparticles to a tryptic digest of a mouse liver lysate, followed by nano-LC-MS/MS and MS/MS/MS analysis for phosphoproteome analysis, which confirmed that the magnetic nanoparticles did show their specificity in selective capture of phosphopeptides even from a complex real sample. In addition, the isolation procedure of phosphopeptides from the complex tryptic digests of proteins was very convenient by applying an extra magnetic field to hold the $\mathrm{Zr}^{4+}-\mathrm{PO}_{3}$-magnetic nanoparticles, which significantly reduced the analysis time and the loss of sample.

\section{Acknowledgments}

The authors gratefully acknowledge financial supports from the National Natural Sciences Foundation of China (no. 20675081, 20735004), the China State Key Basic Research Program Grant (2005CB522701, 2007CB914104), the China High Technology Research Program Grant (2006AA02A309), the Knowledge Innovation program of CAS (KJCX2.YW.HO9, KSCX2-YW-R-079), and the Knowledge Innovation program of DICP (to H. Zou) and the Hundred Talent Program of Chinese Academy of Sciences (to $\mathrm{R}$. $\mathrm{Wu}$ ).

\section{References}

1. Hunter, T. Signaling-2000 and Beyond. Cell 2000, 100, 113-127.

2. Giorgianni, F.; Beranova-Giorgianni, S.; Desiderio, D. M. Identification and Characterization of Phosphorylated Proteins in the Human Pituitary. Proteomics 2004, 4, 587-598.

3. Mann, M.; Jensen, O. N. Proteomic Analysis of Post-Translation Modification. Nat. Biotechnol. 2003, 21, 255-261.

4. Jin, W. H.; Dai, J.; Zhou, H.; Xia, Q. C.; Zou, H. F.; Zeng, R. Phosphoproteome Analysis of Mouse Liver Using Liquid Chromatograph Coupled to MS2/MS3. Rapid Commum. Mass Spectrom. 2004, 19, 3626-3632.

5. McLachlin, D. T.; Chait, B. T. Analysis of Phosphorylated Proteins and Peptides by Mass Spectrometry. Curr. Opin. Chem. Biol. 2001, 5, 591-602.

6. Bennet, K. L.; Stensballe, A.; Podtelejnikov, A. V.; Moniatte, M.; Jensen, O. N. Phosphopeptide Detection and Sequencing by Matrix-Assisted Laser Desorption/Ionization Quadrupole Time-of-Fight Tandem Mass Spectrometry. J. Mass Spectrom. 2002, 37, 179-190.

7. Oda, Y.; Nagasu, T.; Chait, B. T. Enrichment Analysis of Phosphorylated Proteins as a Tool for Probing the Phosphoproteome. Nat. Biotechnol. 2001, 19, 379-382.
8. Zhou, H.; Watts, J. D.; Aebersold, R. A Systematic Approach to the Analysis of Protein Phosphorylation. Nat. Biotechnol. 2001, 19, 375-382.

9. Knight, Z. A.; Schilling, B.; Row, R. H.; Kenski, D. M.; Gibson, B. W.; Shokat, K. M. Phosphospecific Proteolysis for Mapping Sites of Protein Phosphorylation. Nat. Biotechnol. 2003, 21, 1047-1054.

10. Pandey, A.; Podtelejnikov, A. V.; Blagoev, B.; Bustelo, X. R.; Mann, M. Lodish, H. F. Analysis of Receptor Signaling Pathways by Mass Spectrometry: Identification of Vav-2 as a Substrate of the Epidermal and Platelet-Derived Growth Factor Receptors. Proc. Natl. Acad. Sci. U.S.A 2000, 97, 179-184.

11. Conrads, T. P.; Veenstra, T. D. An Enriched Look at Tyrosine Phosphorylation. Nat. Biotechnol. 2005, 19, 379-382.

12. Beausoleil, S. A.; Jedrychowski, M.; Schwartz, D.; Elias, J. E.; Villen, J.; Li, J.; Cohn, M. A.; Cantley, L. C.; Gygi, S. P. Large-Scale Characterization of HeLa Cell Nuclear Phosphoproteins. Proc. Natl. Acad. Sci. U.S.A. 2004, 101, 12130-12135.

13. Ballif, B. A.; Villen, J.; Beausoleil, S. A.; Schwartz, D.; Gygi, S. P. Phosphoproteomic Analysis of the Developing Mouse Brain. Mol. Cell. Proteom. 2004, 3, 1093-1101.

14. Nuhse, T. S.; Stensballe, A.; Jensen, O. N.; Peck, S. C. Large-Scale Analysis of in Vivo Phosphorylated Membrane Proteins by Immobilized Metal Ion Affinity Chromatography and Mass Spectrometry. Mol. Cell. Proteom. 2003, 2, 1234-1243.

15. Larsen, M. R.; Thingholm, T. E.; Jensen, O. N.; Roepstorff, P.; Jorgensen, T. J. D. Highly Selective Enrichment of Phosphorylated Peptides from Peptide Mixtures Using Titanium Dioxide Microcolumns. Mol. Cell. Proteom. 2005, 4, 873-886.

16. Kweon, H. K.; Hakansson, K. Selective zirconium dioxide-based enrichment of phosphorylated peptides for mass spectrometric analysis. Anal. Chem. 2006, 78, 1743-1749.

17. Chen, C. T.; Chen, Y. C. Fe3O4/TiO2 Core/Shell Nanoparticles as Affinity Probes for the Analysis of Phosphopeptides Using TiO2 Surface-Assisted Laser Desorption/Ionization Mass Spectrometry. Anal. Chem. 2005, 77, 5912-5919.

18. Lo, C. Y.; Chen, W. W.; Chen, C. T.; Chen, Y. C. Rapid Enrichment of Phosphopeptides from Tryptic Digests of Proteins Using Iron Oxide Nanocomposites of Magnetic Particles Coated with Zirconia as the Concentrating Probes. J. Proteome Res. 2007, 6, 887-893.

19. Zhou, H. J.; Tian, R. J.; Ye, M. L.; Xu, S. Y.; Feng, S.; Pan, C. S.; Jiang, X. G.; Li, X.; Zou, H. F. Highly specific enrichment of phosphopeptides by zirconium dioxide nanoparticles for phosphoproteome analysis. Electrophoresis 2007, 28, 2201-2215.

20. Posewitz, M. C.; Tempst, P. Immobilized gallium (III) affinity chromatography of phosphopeptides. Anal. Chem. 1999, 71, 2883-2892.

21. Figeys, D.; Gygi, S. P.; Zhang Y.; Watts, J.; Gu, M.; Aebersold, R. Electrophoresis combined with novel mass spectrometry techniques: Powerful tools for the analysis of proteins of proteomes. Electrophoresis 1998, 19, 1811-1818.

22. Moser, K.; White, F. M. Phosphoproteomic Analysis of Rat Liver by High Capacity IMAC and LC-MS/MS. J. Proteome Res. 2006, 5, 98-104.

23. Feng, S.; Ye, M. L.; Zhou, H. J.; Jiang, X. G.; Jiang, X. N; Zou, H. F.; Gong, B. Immobilized Zirconium Ion Affinity Chromatography for Specific Enrichment of Phosophopeptides in Phosphoproteome Analysis. Mol. Cell. Proteom. 2007, 6, 1656-1665.

24. Stensballe, A.; Andersen, S.; Jensen, O. N. Characterization of Phosphoproteins from Electrophoretic Gels by Nanoscale Fe(III) Affinity Chromatography with Off-Line Mass Spectrometry Analysis. Proteomics 2001, 1, 207-222.

25. Rossi, L. M.; Quach, A. D.; Rosenzweig, Z. Glucose Oxidase-Magnetite Nanoparticle Bioconjugate for Glucose Sensing J. Anal. Bioanal. Chem. 2004, 380, 606-613.

26. Graham, D. L.; Ferreira, H. A.; Freitas, P. P. Magnetoresistive-Based Biosensors and Biochips. J. Trends Biotechnol. 2004, 22, 455-462.

27. Zhao, W. R.; Gu, J. L.; Zhang, L. X.; Chen, H. R.; Shi, J. L. Fabrication of Uniform Magnetic Nanocomposite Spheres with a Magnetic Core/ Mesoporous Silica. J. Am. Chem. Soc. 2005, 127, 8916-8917.

28. Xu, C.; Xu, K.; Gu, H.; Zheng, R.; Liu, H.; Zhang, X.; Guo, Z.; Xu, B. Dopamine as a Robust Anchor to Immobilize Functional Molecules on the Iron Oxide Shell of Magnetic Nanoparticles. J. Am. Chem. Soc. 2004, 126, 9938-9939.

29. Horak, D.; Babic, M.; Mackova, H.; Benes, M. J. Preparation and Properties of Magnetic Nano- and Microsized Particles for Biological and Environmental Separations. J. Sep. Sci. 2007, 30, 1751-1772.

30. Tan, F.; Zhang, Y. J.; Wang, J. L.; Wei, J. Y.; Qin, P. B.; Cai, Y.; Qian, X. H. Specific Capture of Phosphopeptides on Matrix-Assisted Laser Desorption/Ionization Time-of-Flight Mass Spectrometry Targets Modified by Magnetic Affinity Nanoparticles. Rapid Commun. Mass Spectrom. 2007, $21,2407-2414$.

31. Kjelistrom, S.; Jensen, O. N. Phosphoric Acid as a Matrix Additive for MALDI MS Analysis of Phosphopeptides and Phosphoproteins. Anal. Chem. 2004, 76, 5109-5117.

32. Eng, J. K.; McCormack, A. L.; Yates, J. R. III. An Approach to Correlate Tandem Mass Spectral Data of Peptides with Amino Acid Sequences in a Protein Database. J. Am. Soc. Mass Spectrom. 1994, 5, 976-989.

33. Wolters, D. A.; Washburn, M. P.; Yates, J. R. III. An Automated Multidimensional Protein Identification Technology for Shotgun Proteomics. Anal. Chem. 2001, 73, 5683-5690.

34. Washburn, M. P.; Wolters, D.; Yates, J. R. Large-Scale Analysis of the Yeast Proteome by Multidimensional Protein Identification Technology. Nat. Biotechnol. 2001, 19, 242-247. 
35. Dai, J.; Shieh, C. H.; Sheng, Q. H.; Zhou, H.; Zeng, R. Proteomic Analysis with Integrated Multiple Dimensional Liquid Chromatography/Mass Spectrometry Based on Elution of Ion exchange Column Using $\mathrm{pH}$ steps. Anal. Chem. 2005, 77, 5793-5799.

36. Jiang, X. N.; Han, G. H.; Feng, S.; Jiang, X. G.; Zou, H .F. Automatic Validation of Phosphopeptide Identifications by MS2/MS3 TargetDecoy Search Strategy. J. Proteome Res. 2008, 7, 1640-1649.

37. He, P.; He, H. Z.; Dai, J.; Wang, Y.; Sheng, Q. H.; Zhou, L. P.; Zhang, Z. S.; Sun, Y. L.; Liu, F.; Wang, K.; Zhang, J. S.; Wang, H. X.; Song, Z. M.; Zhang, H. R.; Zeng, R.; Zhao, X. H. The Human Plasma Proteome:
Analysis of Chinese Serum Using Shotgun Strategy. Proteomics 2005, 5, 3442-3453.

38. Imanishi, S. Y.; Kochin, V.; Erikssion, J. E. Optimization of Phosphopeptide Elution Conditions in Immobilized Fe(III) Affinity Chromatography. Proteomics 2007, 7, 174-176.

39. Zhou, H. J.; Xu, S. Y.; Ye, M. L.; Feng, S.; Pan, C. S.; Jiang, X. G.; Li, X.; Han, G. H.; Fu, Y.; Zou, H. F. Zirconium PhosphonateModified Porous Silicon for Highly Specific Capture of Phosphopeptides and MALDI-TOF MS analysis. J. Proteome Res. 2006, 5, 24312437 